\title{
Localization of chromosomal DNA sequences homologous to ribosomal gene type I insertion DNA in Drosophila melanogaster
}

\author{
Eduardo S. Cantú* and Helen Gay \\ Division of Biological Sciences, The University of Michigan, Ann Arbor, Michigan 48109, USA
}

\begin{abstract}
Summary. Chromosomal sites which have DNA homology to the $1 \mathrm{~kb}$ (kilobase pair) BamHI restrictable fragment of the $5 \mathrm{~kb}$ type I insertion present in many ribosomal genes in Drosophila melanogaster, were identified by using in situ hybridization and autoradiography. XX and XY complements of polytene chromosomes showed the nucleolus and chromocenter to be heavily labeled. Of the light label over euchromatic regions, the $102 \mathrm{C}$ band of chromosome 4 labeled particularly intensely. In mitotic XX and XY complements, the NORs (nucleolus organizer regions) of both sex chromosomes labeled as did the centromeric heterochromatin of autosomes. Label also appeared less frequently over telomeric and euchromatic regions.
\end{abstract}

\section{Introduction}

Length heterogeneity in the ribosomal genes of D. melanogaster is primarily due to the varying length of insertion DNA in many of these genes (Glover and Hogness 1977; White and Hogness 1977; Wellauer and Dawid 1977; and Pelligrini et al. 1977). The functional role of these elements in gene expression remains undetermined despite considerable characterization of them. It is known that the most prevalent class of type I insertions is found in a very specific site in the $28 \mathrm{~S}$ gene region. These range in size between 0.5 and $6.0 \mathrm{~kb}$ and share sequence homology at the rightmost $0.5 \mathrm{~kb}$ region (Wellauer and Dawid 1977). Furthermore, type I insertion DNA appears to be randomly distributed among $X$ chromosomal rDNA genes (Wellauer and Dawid 1977) and ribosomal genes containing type I insertions appear to not be transcribed (Laird and Chooi 1976; McKnight and Miller 1976; Long and Dawid 1979). Of the type $I$ insertions, the most common is the $5 \mathrm{~kb}$ class which seems to be limited to the X-NOR (Tartof and Dawid 1976; Wellauer and Dawid 1977). Since type I insertion sequences have been detected in genomic and chromosomal sites not associated with ribosomal genes (Dawid and Botchan 1977; Kidd and Glover 1980; Peacock et al. 1981), these DNA elements may not be rDNA specific. We sought to determine whether $1 \mathrm{~kb} B a m \mathrm{HI}$ restrictable fragments which include the portion common to all classes of type I insertions are X-NOR specific (and not found in the Y-

\footnotetext{
* Present address: Kleberg Cytogenetics and Prenatal Diagnosis Laboratory, Department of Medicine, Baylor College of Medicine, One Baylor Plaza, Houston, Texas 77030, USA

Offprint requests to: E.S. Cantú
}

NOR) and whether these insertions could be found in chromosomal sites not associated with ribosomal genes using the techniques of in situ hybridization and autoradiography.

\section{Materials and methods}

The $1 \mathrm{~kb}$ Bam $\mathrm{HI}$ restriction fragment of the $5.4 \mathrm{~kb}$ type I insertion in recombinant plasmid pDmra56 (Fig. 1A) was used to transcribe ${ }^{3} \mathrm{H}$-cRNA probe used for in situ hybridization. Recombinant plasmids pDmra56 and pDmrY22 (which has no type I insertions) were gifts of Dr. Igor B. Dawid (Chief, Department of Biochemistry, NIH, Bethesda, Maryland) and detailed characterization of these have been reported (Dawid et al. 1978). Preparative quantities of the $1 \mathrm{~kb}$ BamHI restrictable type I insertion fragment were obtained by using the method of El-Gewely and Helling (1980). "Insertionless" rDNA used for control experiments was isolated from pDmrY22 (Fig. 1B) using the same protocol. The purity of the isolated recombinant plasmids and DNA fragments of interest were monitored using electron microscopy and analytical agarose gel electrophoresis. Recombinant DNA molecules were handled under EK-P2 level of containment as specified by the National Institutes of Health. Tritium labeled cRNA was synthesized following the procedure of Gall and Pardue (1971), and involved in vitro transcription of template DNA in the presence of tritiated nucleotide precursors. Specific activities of the ${ }^{3} \mathrm{H}$ cRNA probes synthesized were approximately $1.0 \times 10^{8} \mathrm{dpm} / \mu \mathrm{g}$.

Salivary gland polytene chromosomes were prepared as described by Pardue and Gall (1976) from Swedish b strain of $D$. melanogaster larvae which had been sexed by examining their gonads. Polytene chromosomes were checked to confirm initial sex assignments, based on the criterion that the $\mathrm{X}$ arm in $\mathrm{XY}$ complements does not polytenize to the extent found in XX complements and therefore appears thinner and stains fainter. Mitotic chromosomes were prepared from early embryos $(0-4 \mathrm{~h})$ using a method patterned after the human leukocyte chromosome procedure originally described by Moorehead et al. (1960). Techniques of in situ hybridization and autoradiography were as reported by Pardue and Gall (1975). Autoradiographic exposures ranged between $30-45$ days. After photographic development, slides were Giemsa stained. Grain count analysis entailed evaluating silver grains appearing over chromosomes compared to silver grains appearing over non-chromosomal areas. 

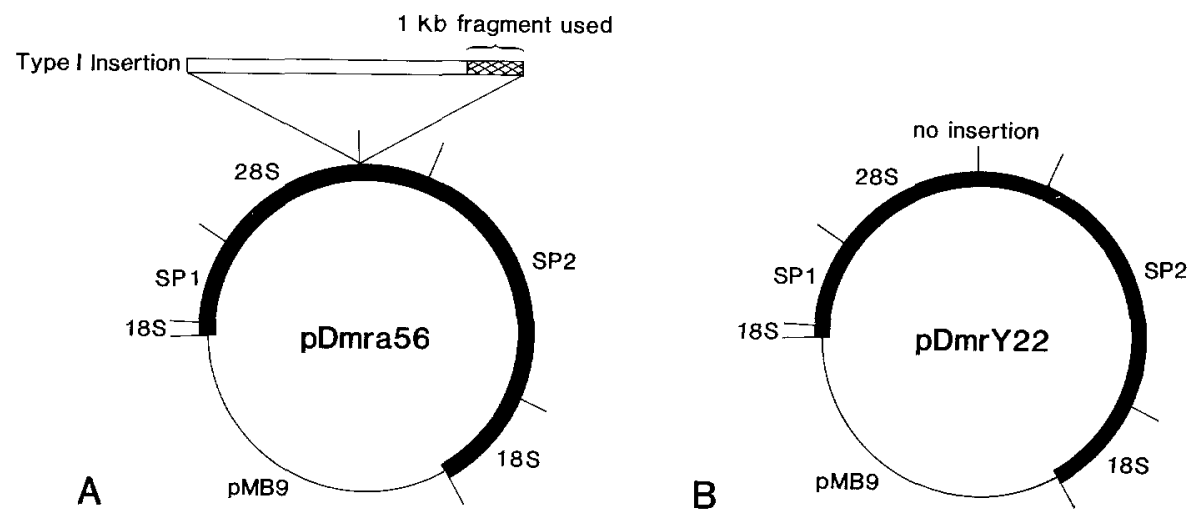

Fig. 1 A, B. Circular maps of recombinant plasmids pDmra56 (shown in A) and pDmrY22 (shown in B) indicating the fragments used as template for the synthesis of tritiated cRNA probes for in situ hybridization. From pDmra56 was isolated the $1 \mathrm{~kb} \mathrm{BamHI}$ restrictable fragment shown as the rightmost (cross-hatched bar, part of the $5 \mathrm{~kb}$ type I insertion. From pDmrY22 was isolated "insertionless" rDNA (solid bar, a) after EcoRI digestion. Plasmid pMB9 DNA is shown as a solid line, $\longrightarrow$ )

Table 1. Autoradiographic distribution of silver grains over $D$. melanogaster polytene chromosomes after in situ hybridization with ${ }^{3} \mathrm{H}-\mathrm{cRNA}$ synthesized from the $1 \mathrm{~kb}$ BamHI restrictable type I insertion DNA

\begin{tabular}{|c|c|c|c|c|c|c|c|c|c|}
\hline Observations & Nucleolus & $\begin{array}{l}\text { Chromo- } \\
\text { center }^{\mathrm{a}}\end{array}$ & $\mathrm{X}$ & $2 \mathrm{~L}$ & $2 \mathrm{R}$ & $3 \mathrm{~L}$ & $3 R$ & 4 & $\begin{array}{l}\text { Total } \\
\text { chromosome } \\
\text { area } \\
\text { studied }^{\text {b }}\end{array}$ \\
\hline Number of observations & 26 & 26 & 26 & 26 & 26 & 26 & 26 & 26 & 26 \\
\hline $\begin{array}{l}\text { Average \# of silver } \\
\text { grains found }\end{array}$ & 48 & 33 & 28 & 25 & 26 & 32 & 29 & 4 & 226 \\
\hline $\begin{array}{l}\text { Number of silver grains } \\
\text { not due to background }\end{array}$ & $\begin{array}{l}35 \\
(27.0 \%)\end{array}$ & $\begin{array}{l}20 \\
(16.0 \%)\end{array}$ & $\begin{array}{l}15 \\
(12.0 \%)\end{array}$ & $\begin{array}{l}12 \\
(9.5 \%)\end{array}$ & $\begin{array}{l}12 \\
(9.5 \%)\end{array}$ & $\begin{array}{l}18 \\
(14.0 \%)\end{array}$ & $\begin{array}{l}12 \\
(9.0 \%)\end{array}$ & $\begin{array}{l}4 \\
(3.0 \%)\end{array}$ & $\begin{array}{l}128 \\
(100 \%)\end{array}$ \\
\hline
\end{tabular}

a Consisting of $\alpha$ and $\beta$ heterochromatic portions of the chromosome arms, plus the $\mathrm{Y}$ chromosome (and occasionally possible inclusion of chromosome 4)

b Including the nucleolus and the chromocenter

c In order to determine the expected \# of background silver grains over the particular chromosomal regions considered, study areas were selected in which the cytological material occupied $50 \%$ of this area or less and the remaining area was blank. By multiplying the total number of silver grains over the blank region by a normalized fractional value each chromosomal component occupied, a value estimating the number of expected silver grains over particular chromosomal regions could be determined

\section{Results and discussion}

Localized label over polytene and mitotic chromosomes indicated chromosomal sites having DNA homology to the $1 \mathrm{~kb}$ BamHI restrictable type I insertion DNA. Grain count analysis for polytene chromosomes is summarized in Table 1. Of the label found over polytene chromosomes, approximately $27 \%$ occurred over the nucleolus, and about $16 \%$ was found over the chromocenter (as clusters at the bases of each chromosome arm, labeling both the $\alpha$ and $\beta$ heterochromatin), and the remaining label appeared over the euchromatic arms as light and dispersed label except for the $102 \mathrm{C}$ band of chromosome 4 which labeled intensely. Figure 2 provides several autoradiographs showing localized labeling of the nucleolus, the chromocenter and band $102 \mathrm{C}$ of chromosome 4 .

Results from the polytene chromosomes (Table 1) show that nucleoli from both XY (Fig. 2) and XX complements labeled with about the same intensity. These results are surprising since nucleoli from $\mathrm{XY}$ polytene chromosome complements have been shown to be Y-chromosome derived (Endow and Glover 1979), and since the major $5 \mathrm{~kb}$ type I insertion class is X-NOR specific (Tartof and Dawid 1976; Wellauer and Dawid 1977; Dawid et al. 1978). Our results provide clear empirical evidence of ribosomal type I insertion homology in XY polytene nucleoli. We interpret these findings to suggest that the Y-NOR includes some rDNA genes which have the short length type I insertions which had been previously undetected and that only the long length type I insertions may be X-NOR specific. More than $50 \%$ of the label appeared over the euchromatic regions of polytene chromosomes (Table 1). Label found over the euchromatic regions proved to be considerably higher than background and indicated some degree of sequence homology in euchromatin although not as high as that found for the nucleolus, chromocenter and $102 \mathrm{C}$ band of chromosome 4 . Control probe, ${ }^{3} \mathrm{H}-28 \mathrm{~S}$ rRNA, labeled only the nucleolus and ${ }^{3} \mathrm{H}$-cRNA (synthesized from "insertionless" rDNA) labeled the nucleolus intensely, the arms with a low unspecific pattern, but did not label the chromocenter.

Grain count analysis for experiments in which embryonic mitotic chromosomes were in situ hybridized with the $1 \mathrm{~kb}$ type I insertion probe revealed the greatest sequence homology to the NORs of sex chromosomes X and Y, but particularly higher for Xs. Label was also detected over centromeric heterochromatin of the $\mathrm{X}$ and autosomes 2 and 3 , and to a lesser extent over telomeric and euchromatic 


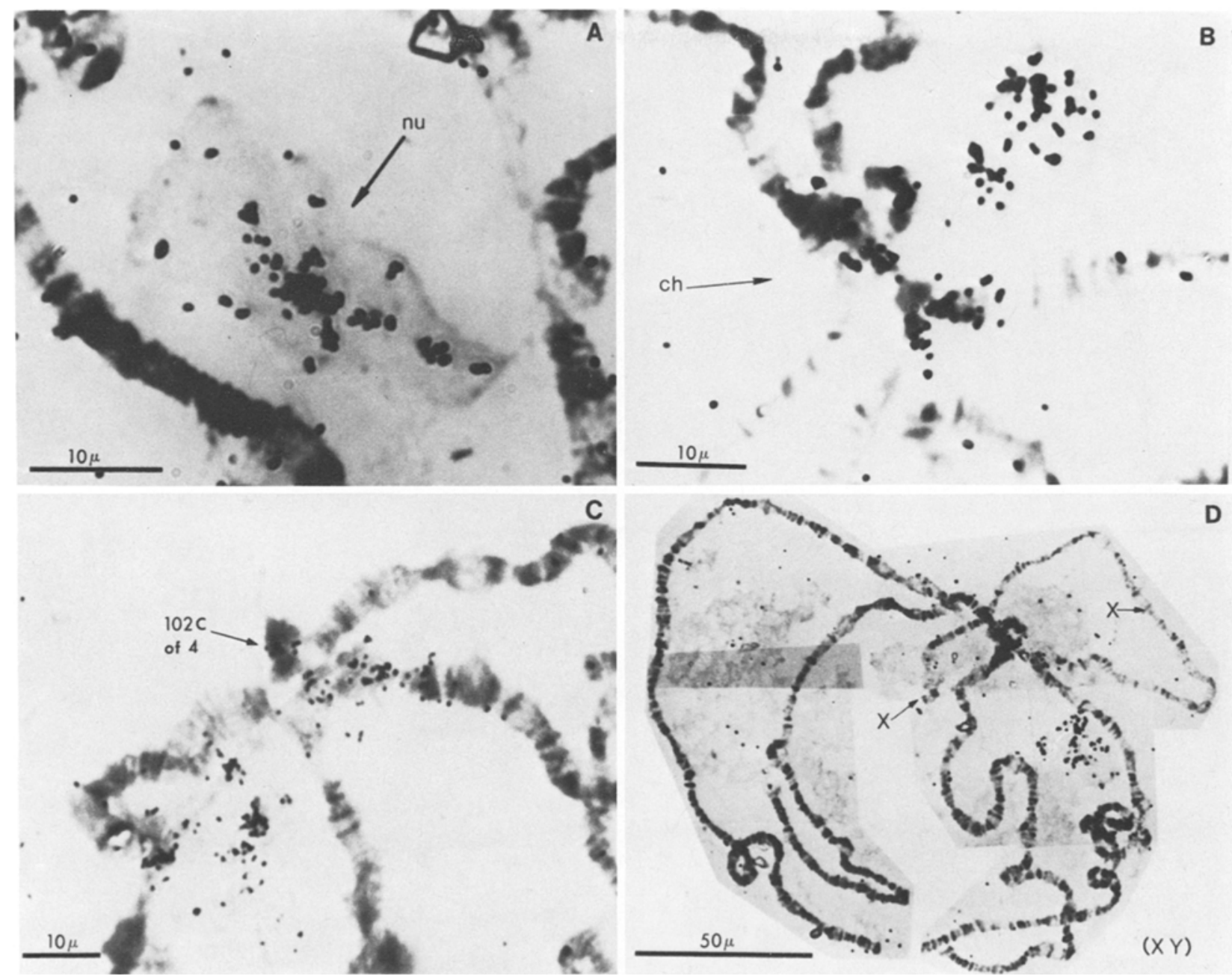

Fig. 2 A-D. Autoradiographs of $X Y$ polytene chromosome complements showing the general labeling pattern found after in situ hybridization with ${ }^{3} \mathrm{H}$-cRNA $\left(1.0 \times 10^{8} \mathrm{dpm} / \mu \mathrm{g}\right)$ synthesized from the $1 \mathrm{~kb}$ BamHI restrictable type I insertion DNA. Both XX and XY chromosome complements showed the same pattern of clusters of silver grains over the nucleolus (arrow, nu) shown in $\mathbf{A}$, over heterochromatic bases of each arm at the chromocenter including the central heterochromatic core (arrow, ch) shown in B and over 102C of chromosome 4 (arrow, 4) shown in $\mathbf{C}$. Shown in $\mathbf{D}$ is a complete XY polytene chromosome set and points out the X which is differentially less polytenized

Table 2. Autoradiographic distribution of silver grains over embryonic mitotic chromosomes of $D$. melanogaster after in situ hybridization with ${ }^{3} \mathrm{H}$-cRNA synthesized from the $1 \mathrm{~kb}$ BamHI restrictable type I insertion DNA

\begin{tabular}{|c|c|c|c|c|c|c|c|}
\hline \multirow[t]{3}{*}{ Sex } & \multirow{3}{*}{$\begin{array}{l}\text { Number } \\
\text { of diploid } \\
\text { cell }\end{array}$} & \multicolumn{6}{|c|}{ Total number of silver grains over } \\
\hline & & \multicolumn{2}{|c|}{ Sex chromosomes } & \multicolumn{3}{|c|}{ Autosomes } & \multirow{2}{*}{$\begin{array}{l}\text { Total } \\
\text { chromosomal } \\
\text { area } \\
\text { studied }^{\mathrm{a}}\end{array}$} \\
\hline & & $\mathrm{XX}$ & $X Y$ & $\begin{array}{l}\text { 2nd } \\
\text { pair }\end{array}$ & $\begin{array}{l}\text { 3rd } \\
\text { pair }\end{array}$ & $\begin{array}{l}\text { 4th } \\
\text { pair }\end{array}$ & \\
\hline $\begin{array}{l}\text { Female } \\
\text { (averages) }\end{array}$ & 92 & $\begin{array}{l}286 \\
(3.1)\end{array}$ & & $\begin{array}{l}194 \\
(2.1)\end{array}$ & $\begin{array}{l}239 \\
(2.5)\end{array}$ & $\begin{array}{c}9 \\
(0.1)\end{array}$ & $\begin{array}{l}728 \\
(7.8)\end{array}$ \\
\hline $\begin{array}{l}\text { Male } \\
\text { (averages) }\end{array}$ & 62 & & $\begin{array}{l}167 \\
(2.7)\end{array}$ & $\begin{array}{l}105 \\
(1.7)\end{array}$ & $\begin{array}{l}191 \\
(3.1)\end{array}$ & $\begin{array}{l}30 \\
(0.5)\end{array}$ & $\begin{array}{l}493 \\
(8)\end{array}$ \\
\hline $\begin{array}{l}\text { Total } \\
\text { (averages) }\end{array}$ & 154 & $\begin{array}{l}453 \\
(3)\end{array}$ & & & $\begin{array}{l}768 \\
(5)\end{array}$ & & $\begin{array}{c}1221 \\
(8)\end{array}$ \\
\hline (percentages) & - & $(37 \%)$ & & & $(63 \%)$ & & $(100 \%)$ \\
\hline
\end{tabular}

${ }^{\text {a }}$ Comparison of label appearing over chromosomes to label appearing over blank areas suggests that only 1 out of the average 8 grains is background 


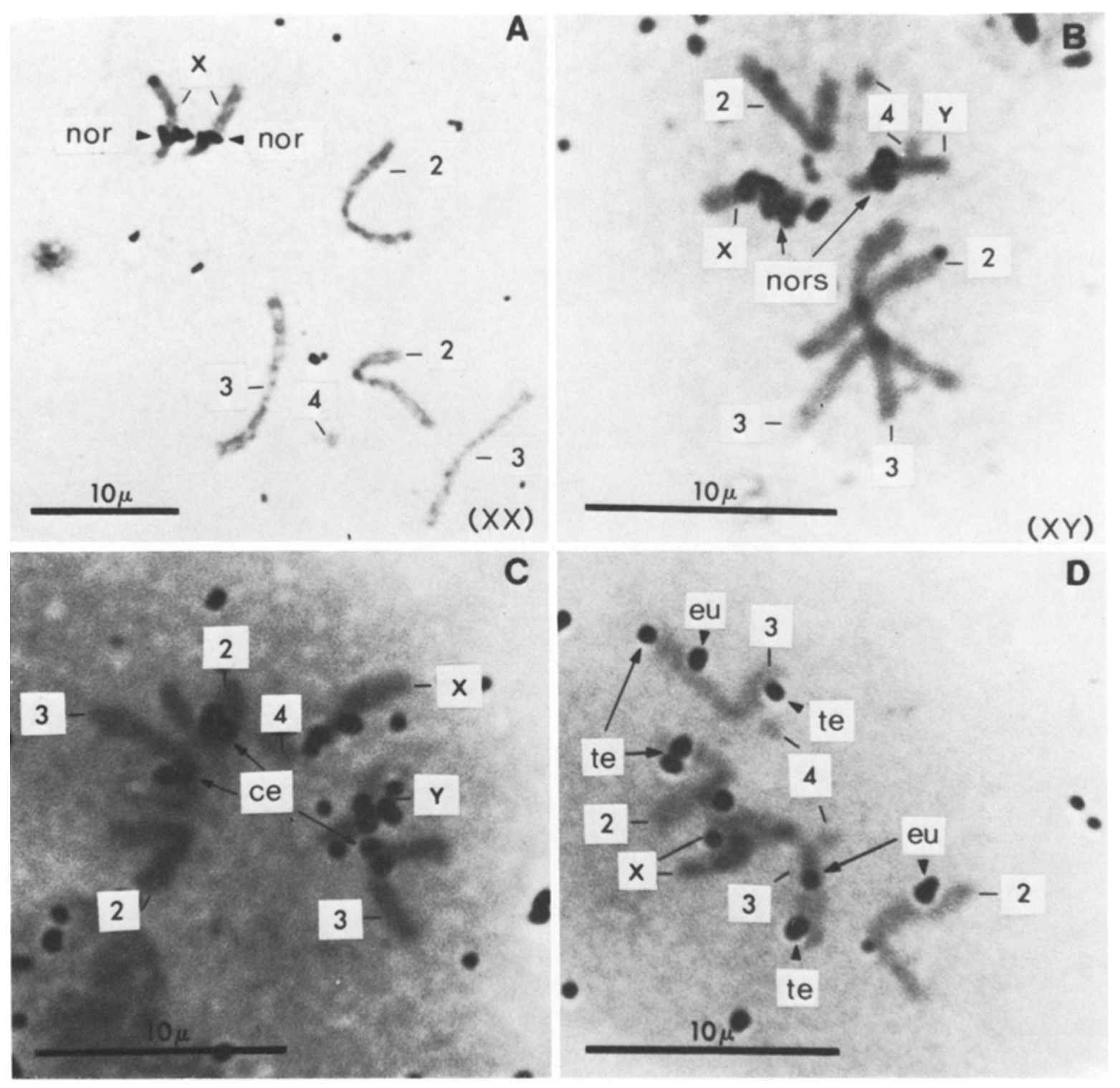

Fig. 3 A-D. Autoradiographs of embryonic mitotic chromosomes after in situ hybridization with ${ }^{3} \mathrm{H}-\mathrm{cRNA}\left(1.0 \times 10^{8} \mathrm{dpm} / \mu \mathrm{g}\right) \mathrm{synthesized}$ from the $1 \mathrm{~kb}$ BamHI restrictable type $I$ insertion DNA. In $\mathbf{A}$ is shown an $X X$ and in $\mathbf{B}$ is shown an $X Y$ mitotic complement in which localized labeling over the NORs of both sex chromosomes has occurred (arrows). In C, localized labeling to centromeric heterochromatin of autosomes 2 and 3 can be seen (arrows). And in $\mathbf{D}$, localized label appears over telomeric and euchromatic regions of autosomes 2 and 3 (arrows)

areas of $\mathrm{X}, 2$ and 3 . The level of labeling over the 4 th mitotic chromosome was low and difficult to evaluate. An evaluation of 92 mitotic XX and 62 mitotic XY complements was used for our observations which are summarized in Table 2. Of the total number of silver grains appearing over mitotic chromosomes, about $37 \%$ occurred over the sex chromosomes in XX and XY spreads. In XY complements, the $X$ chromosome was more labeled than the $Y$ chromosome, although both NORs appeared to label. The remaining label $(63 \%)$ appeared over the autosomes. The ${ }^{3} \mathrm{H}$-cRNA probe (synthesized from the "insertionless" rDNA) hybridized exclusively to the NORs of the sex chromosomes. Figure 3 includes autoradiographs showing examples of insertion I hybridization to NORs of sex chromosomes (A and $\mathrm{B}$ ), centromeric regions (C) and also to telomeric and euchromatic regions (D).
Autoradiographic results from in situ hybridization of D. melanogaster polytene and mitotic chromosomes show that sequence homology to type I insertion DNA can occur not only in ribosomal genes, but also in centromeric heterochromatin and perhaps even in telomeric and euchromatic regions. These findings are in accord with those reported by Dawid and Botchan (1977) that DNA sequences homologous to type I insertions occur outside NORs, and with the observations of Kidd and Glover (1980) that a cloned fragment which includes five tandemly arranged elements having sequence homology to type I insertions is found in the chromocenter of polytene chromosomes. We confirm results reported by Peacock et al. (1981) that type I insertion DNA homology occurs not only in the nucleolus of the polytene chromosomes and in X-NORs of mitotic chromosomes, but also in the chromocenter and in band $102 \mathrm{C}$ 
of the 4th arm in polytene chromosomes. However, by using the $1 \mathrm{~kb}$ BamHI restrictable type I insertion fragment to transcribe ${ }^{3} \mathrm{H}$-cRNA probe rather than the major $5 \mathrm{~kb}$ type I insertion fragment used by Peacock et al. (1981) we detected previously unreported type I insertion DNA homology to other chromosomal regions. We found type I insertion DNA homology in the Y-NOR, centromeric heterochromatin and to a lesser extent in telomeric and euchromatic regions of mitotic chromosomes and also in XY-nucleoli and to a limited extent in euchromatic regions of polytene chromosomes.

Our finding that type I insertions occur in heterochromatin which is known to cause genetic inactivation in the classical case of position-effect variegation is in agreement with the idea that ribosomal genes containing the type I insertions are not transcribed (Laird and Chooi 1976; McKnight and Miller 1976; Long and Dawid 1979). Whether or not type I insertion DNA homology outside ribosomal genes is exclusively contained in heterochromatin is difficult to judge since heterochromatin is not conspicuously obvious in euchromatic and telomeric regions where we found some degree of homology. It is possible that morphologically undetectable heterochromatin occurs at these sites in the form of telomeric and intercalary heterochromatin. Ananiev et al. (1978), for example, have shown that fragments Dm225 and Dm234 are widely distributed elements in D. melanogaster, and appear to be structurally associated with intercalary heterochromatin. We were unable to correlate particular sites of intercalary heterochromatin with sites showing homology to type I insertions. It was noted, however, that the fluorescent pattern found by Adkisson et al. (1971) was very similar to the autoradiographic pattern we found and included fluorescence at the chromocenter and band (102D) of chromosome 4 .

An alternative link between type I insertion DNA and D. melanogaster chromosome organization may involve mobile elements (for review see Spradling and Rubin 1981). Pardue and Dawid (1981) have reported that many sites in the chromosomes of D. melanogaster are homologous to two DNA fragments which flank ribosomal "insertionlike" DNA. They also suggested that these are mobile elements, but that they may be distinct from other classes of transposable elements in D. melanogaster (Dawid et al. 1981). Our results also support the notion that "insertionlike" sequences can be flanked by non-ribosomal gene DNA.

It is impossible to attribute a functional role to type I insertion DNA from our results. If mobile genetic elements and proviruses have significant similarities as Temin (1980) suggests, type I insertions may represent nothing more than "accidental" integrations of extraneous DNA elements which, though not representing an integral part of the $D$. melanogaster genome, may nonetheless, effect essential chromosomal properties.

Acknowledgements. We wish to thank Dr. I.B. Dawid (Chief, Department of Biochemistry, NIH, Bethesda, Maryland) for the gifts of recombinant plasmids pDmra56 and pDmrY22. A debt of gratitude is due Dr. R.B. Helling and Dr. M.R. El-Gewely for their role in the preparation of hybridization probe molecules. Dr. G.P. Holmquist and Dr. R.P. Donahue provided critical appraisals of our manuscript. This study was supported in part by NIH grant No. GM-10499.

\section{References}

Adkisson KP, Perreault WJ, Gay H (1971) Differential fluorescent staining of Drosophila chromosomes with quinacrine mustard. Chromosoma 34:190-205

Ananiev EV, Gvozdev VA, Ilyin YuV, Tchurikow NA, Georgiev GP (1978) Reiterated genes with varying locations in intercalary heterochromatic regions of $D$. melanogaster chromosomes. Chromosoma 70:1-17

Dawid IB, Botchan P (1977) Sequences homologous to ribosomal insertions occur in the Drosophila genome outside the nucleolus organizer. Proc Natl Acad Sci USA 74:4233-4237

Dawid IB, Wellauer PK, Long EO (1978) Ribosomal DNA in Drosophila melanogaster. I. Isolation and characterization of cloned fragments. J Mol Biol 126:749-768

Dawid IB, Long EO, DiNocera PP, Pardue ML (1981) Ribosomal insertion-like elements in Drosophila melanogaster are interspersed with mobile sequences. Cell 25:399-408

El-Gewely MR, Helling RB (1980) Preparative separation of DNAethidium bromide complexes by zonal density gradient centrifugation. Anal Biochem 102:423-428

Endow SA, Glover DM (1979) Differential replication of ribosomal gene repeat in polytene nuclei of Drosophila. Cell 17:597-605

Gall JG, Pardue ML (1971) Nucleic acids, Part D. In: Grossman L, Moldave K (eds) Methods in enzymology, vol 21. Academic Press, New York, pp 470-480

Glover DM, Hogness DS (1977) A novel arrangement of the $18 \mathrm{~S}$ and $28 \mathrm{~S}$ sequences in a repeating unit of Drosophila melanogaster rDNA. Cell 10:167-176

Kidd SJ, Glover DM (1980) A DNA segment from Drosophila melanogaster which contains five tandemly repeating units homologous to the major rDNA insertion. Cell 19:103-119

Laird DD, Chooi WY (1976) Morphology of transcription units in Drosophila melanogaster. Chromosoma 58:193-218

Long EO, Dawid IB (1979) Expression of ribosomal DNA insertion in Drosophila melanogaster. Cell 18:1185-1196

McKnight SL, Miller OL (1976) Ultrastructural patterns of RNA synthesis during early embryogenesis of Drosophila melanogaster. Cell 8:305-319

Moorehead PS, Novell PC, Mellman WJ, Battips DM, Hungerford DA (1960) Chromosome preparations of leukocytes cultured from human peripheral blood. Exptl Cell Res 20(3):613-616

Pardue ML, Gall JG (1975) Nucleic acid hybridization to the DNA of cytological preparations. In: Prescott DM (ed) Methods in cell biology, vol X. Academic Press, New York, pp 1-16

Pardue ML, Dawid IB (1981) Chromosomal localization of two DNA segments that flank ribosomal insertion-like sequences in Drosophila: flanking sequences are mobile elements. Chromosoma (Berl) 83:29-43

Peacock WJ, Appels R, Endow SA, Glover DM (1981) Chromosomal distribution of the major insert in Drosophila melanogaster 28S rRNA genes. Genet Res Camb 37:209-214

Pellegrini M, Manning J, Davidson N (1977) Sequence arrangement of the rDNA of Drosophila melanogaster. Cell 10:213-22

Spradling AC, Rubin GM (1981) Drosophila genome organization: conserved and dynamic aspects. Annu Rev Genet 15:219-264

Tartof KD, Dawid IB (1976) Similarities and differences in the structure of $\mathrm{X}$ and $\mathrm{Y}$ chromosome rRNA genes of Drosophila. Nature 263:27-30

Temin HM (1980) Origin of retroviruses from cellular moveable genetic elements Cell 21:599-600

Wellauer PK, Dawid IB (1977) The structural organization of ribosomal DNA in Drosophila melanogaster. Cell 10:193-212

White RL, Hogness DS (1977) R looping of the $18 \mathrm{~S}$ sequences in the long and short repeating units of Drosophila melanogaster rDNA. Cell 10:177-192

Communicated by M.M. Green

Received April 18, 1984 